Research Article

\title{
Research on the Seam Formation Mechanism of Elliptical Bipolar Linear Directional Blasting Based on the SPH-FEM Coupling Method
}

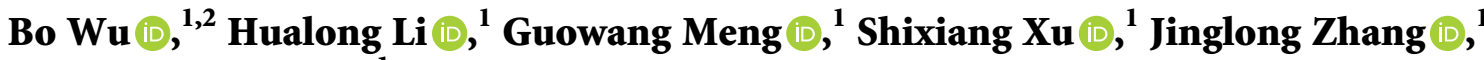 \\ and Yaozhong Cui $\mathbb{D}^{1}$ \\ ${ }^{1}$ College of Civil Engineering and Architecture, Guangxi University, Nanning 530004, China \\ ${ }^{2}$ School of Civil and Architectural Engineering, East China University of Technology, Nanchang 330013, China \\ Correspondence should be addressed to Hualong Li; 2894680262@qq.com and Shixiang Xu; 603559081@qq.com
}

Received 28 June 2021; Revised 22 November 2021; Accepted 15 December 2021; Published 31 December 2021

Academic Editor: Sami El-Borgi

Copyright ( $\odot 2021$ Bo Wu et al. This is an open access article distributed under the Creative Commons Attribution License, which permits unrestricted use, distribution, and reproduction in any medium, provided the original work is properly cited.

\begin{abstract}
Rock mass blasting is a complex process that involves the coupling of both discontinuous and continuous media. This paper aims to reveal the dynamic failure process between adjacent boreholes under an elliptical bipolar linear charge structure using the SPHFEM (smooth particle hydrodynamics and finite-element method) coupling algorithm numerical simulation method. The numerical simulation results are compared with the existing experimental results, which proves the rationality of the algorithm. According to the numerical simulation results, the shaped jet will first shock the hole wall and form a stress concentration zone that will guide the formation of cracks during the stress wave propagation process. In the case of double-hole blast loading, there is a tendency for cracks coalescence to develop between adjacent boreholes due to the superposition of stresses between the double holes and the increase in damage and plastic strain. The best blasting results will be achieved with this structure when the distance between adjacent holes is $110 \mathrm{~cm}$. Finally, the superiority of elliptical bipolar linear blasting in engineering blasting was verified through field experiments. The results of this study provide a reference for subsequent applications of elliptical bipolar structures in the field of rock blasting.
\end{abstract}

\section{Introduction}

Solid rock often exists in complex geological environments in large-scale tunnelling and excavation projects, so the drilling and blasting method is still the main construction method for rock tunnel excavation. In recent years, the blasting construction method represented by concentrated energy directional blasting has shown great superiority in large-scale excavation projects such as mineral development and tunnel excavation. The elliptical bipolar linear shaped charge blasting has been applied to many engineering projects. However, there are few studies on the blasting theory of elliptical bipolar linear shaped charge blasting and the law of crack propagation.

The impact process of explosive blast waves is a transient process with high stress [1-4], so it is theoretically difficult to understand the process of rock fracture damage under blasting loading. To reflect the deformation characteristics of rock masses under shaped charge directional blasting, Foster [5] proposed in the early 20th century excavating an axial groove near the borehole wall in advance to control the direction of crack propagation after blasting. In 1952, Williams et al. [6] conducted a theoretical analysis on the problem of first slotting near the borehole and revealed the mechanism of the initial crack on the formation of directional cracks. Shaped energy blasting originated early in Europe and began to be mainly used in the military industry. It has received attention and research from various countries during the First and Second World Wars [7, 8]. The Swedish scholar Bjarnholt et al. [9] introduced the structure of shaped charge into rock blasting and achieved good results in the field of rock blasting, which promoted the 
development of shaped energy directional blasting. In the 1970s, Fourney et al. [10] used a tubular charge with axial slits in the borehole. Many experiments have proven that this structure can indeed achieve good directional rock-breaking effects. Professor Wang and You-zhi [11] first proposed using PVC pipes as energy-concentrating devices in directional blasting experiments of slitting charge bags and studied the structure of energy-concentrating blasting by many experiments. Jian-fei et al. $[12,13]$ used PVC pipes to make a new type of elliptical bipolar shaped charge drug package structure and produced good benefits in the project. Li et al. [14-17] verified the rationality of the structure of an elliptical bipolar linear shaped charge capsule through theoretical analysis, numerical simulation, and experimental verification. Zhu et al. [18] compared shaped energy blasting with ordinary blasting and proved that shaped energy blasting can improve the crack evolution ability in the direction of energy accumulation. Meng et al. [19] used PMMA materials to conduct experiments and revealed the development mechanism of shaped energy jets. Many studies have proven that energy-concentrating structures can form jets that can induce the development of directional cracks.

This research focuses on the study of dynamic crack propagation under elliptical bipolar linear shaped (Figure 1) blasting loads. Figure 1 illustrates the process of fracture formation by elliptical bipolar shaped charge blasting, where a groove is formed after the shaped charge jet shocks the hole wall, and finally, the rock is cracked under tensional stress. Based on the Johnson-Holmquist $(\mathrm{JH})$ constitutive model [20], the SPH-FEM coupling method is adopted. First, comparing and verifying the known parameter model in Banadaki and Mohanty [21], the experimental and numerical simulation results proved the rationality of the parameters. The dynamic evolution process of the elliptical bipolar linear structure burst pattern is reproduced in LSDYNA software and compared with the blasting effect of ordinary blasting. It is proven that the elliptical bipolar linear shaped charge structure has an effect that can result in a certain crack orientation. Finally, the mechanism of doublehole-shaped charge blasting is revealed, and then the distance between holes of the double-hole elliptical bipolar linear shaped charge structure is optimized.

\section{Method}

\subsection{Mechanism of Crack Formation in Rock by Shaped Energy Blasting}

2.1.1. Formation Mechanism of Shaped Jet. When the initiation point of the shaped charge pack is detonated in the shaped charge blasting device, explosives will have a strong chemical reaction to produce blast waves, which will spread uniformly until they touch the shaped charge tube (Figure 2). When the detonation wave reaches the position of radius $R_{0}$, as shown in Figure 3, the shaped charge tube is gradually crushed under the action of the detonation wave and is squeezed into a surface such as CAB. Propelled by the detonation wave, the axial surface of the shaped charge tube

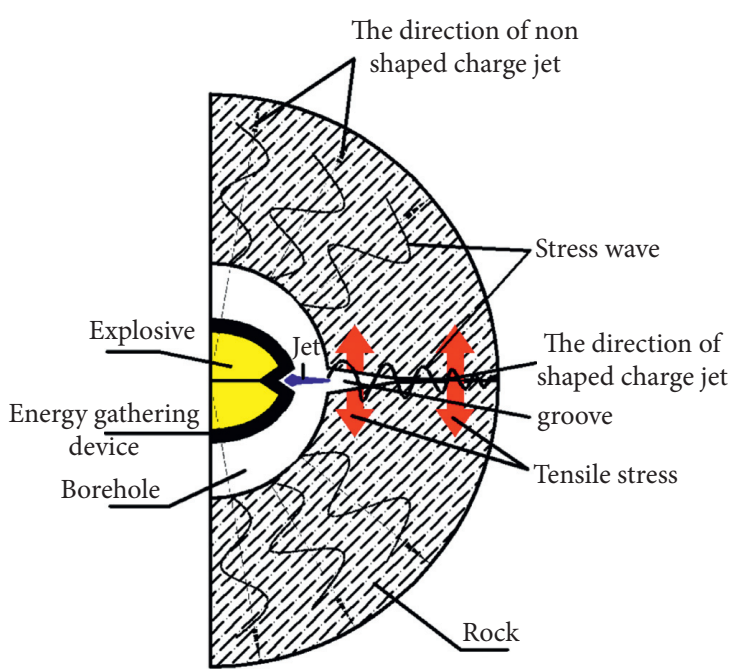

FIgURE 1: Mechanical model of single-hole elliptical and bipolar shaped charge tension blasting.

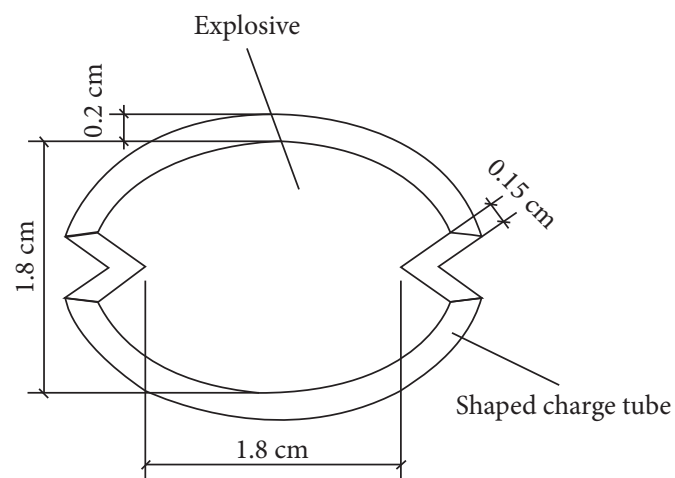

FIGURE 2: Cross section of the shaped charge tube.

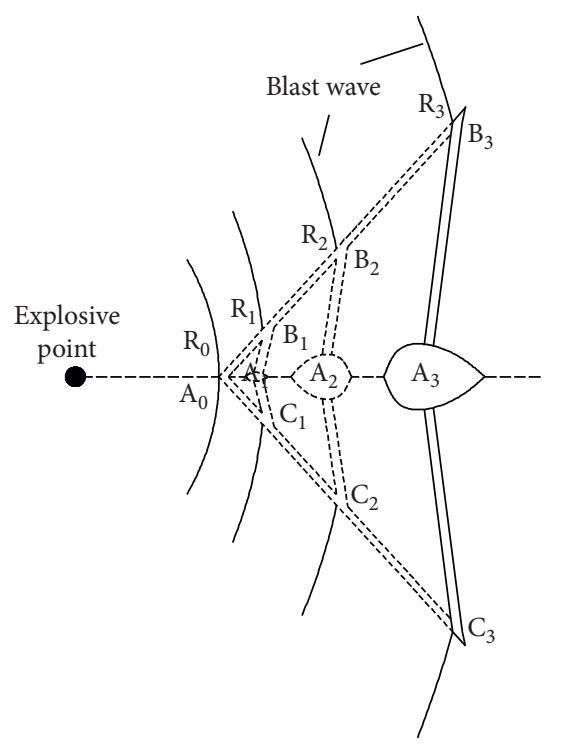

FIgURE 3: The formation process of shaped charge jet.

collides and squeezes at points $A_{1}$ and $A_{2}$ successively and is squeezed into curved surfaces such as $C_{1} A_{1} B_{1}$ and $C_{2} A_{2} B_{2}$ in turn. Eventually, the shaped charge tube forms a shaped 
energy jet under the action of the detonation wave and destroys the borehole under the action of the subsequent detonation wave and detonation pressure gas, thereby guiding the formation of cracks in the shaped charge direction.

2.1.2. Formation of Blast-Induced Cracks. The shaped charge jet formed rapidly after the detonation of the shaped charge pack and shocked the wall of the borehole to form a stress concentration area. The subsequent shock wave shocks to the rock mass, causing the borehole to be subjected to tangential tensile stress in the shaped charge direction, and the detonation wave in the nonshaped charge direction shocks evenly to the borehole wall and squeezes the surrounding rock mass.

The stress intensity factor at the crack tip can be calculated by the following equation [22]:

$$
K_{\mathrm{I}}=\mathrm{PB} \sqrt{\pi(r+L)}+\sigma \sqrt{\pi L} .
$$

$P$ is the pressure applied to the crack tip when the crack propagates. $B$ is a correction coefficient, $r$ is the borehole radius, $L$ is the instantaneous propagation length of radial fissures, and $\sigma$ is tangential tensile stress induced by blasting.

When crack propagation stops, the stress intensity factor at the crack tip can be expressed as

$$
K_{\mathrm{I}}=P_{0} B \sqrt{\pi(r+L)}+\sigma \sqrt{\pi L},
$$

where $P_{0}$ is the pressure applied to the crack tip when the crack propagation arrests.

According to the theory of fracture mechanics, when the stress intensity factor $\left(K_{I}\right)$ at the end of the crack is greater than the fracture toughness $\left(K_{\mathrm{IC}}\right)$ of the rock mass, the crack starts to propagate, and the crack propagation satisfies the formula

$$
P_{0}>\frac{K_{\mathrm{IC}}-\sigma \sqrt{\pi L}}{B \sqrt{\pi(r+L)}} .
$$

With the weakening of the wall strength of the borehole at the edge of the hole, a large amount of explosive gas rapidly expands and enters the rock mass void to form a quasistatic stress field. The crack propagates if the pressure $\mathrm{P}$ formed by the explosive gas at the tip satisfies the following formula:

$$
P \geq \frac{K_{\mathrm{IC}}-\left(\sigma-\sigma_{\max }\right) \sqrt{\pi L}}{B \sqrt{\pi(r+L)}},
$$

where $\sigma_{\max } \max$ is maximum tangential tensile stress.

A shaped charge jet will produce more cracks in the shaped charge direction that will be larger than the tiny cracks produced in other directions. At the end of the blast, a large amount of blasting gas will enter these cracks and exert a tensile effect on the rock mass around the cracks. When the tensile stress exceeds the tensile strength of the rock, the surrounding cracks will extend further. Due to the development of cracks in the shaped charge direction, a large amount of explosive gas will actively influx into these cracks, thereby increasing the rate of evolution of shaped charge directional cracks. According to the principle of energy conservation, this mechanism also plays a role in reducing the development of cracks in the nonshaped charge direction.

2.2. SPH-FEM Coupling Principle. In the numerical simulation of rock blasting, traditional finite-element grids are prone to grid distortion due to large deformation problems during calculations, resulting in a decrease in the calculation accuracy and efficiency of the data during the calculation process. In the end, the calculation result may not converge, and the calculation cannot be completed. Smooth particle hydrodynamics ( $\mathrm{SPH}$ ) is a meshless numerical calculation method. In 1977, Lucy and Gingold et al. $[23,24]$ proposed the basic method of SPH, which was initially applied to solve astrophysics and cosmology problems. As the SPH method does not require mesh, there will be no mesh deformation problems when performing large deformation calculations. Complex constitutive model calculations can be achieved simply and accurately, and it is also suitable for describing material fracture problems under high loading rates. The SPH method is not as computationally efficient as the finite-element method when dealing with small deformation problems. In rock blasting simulation, the area near the borehole of rock blasting will exhibit large deformation in a short period of time, while the distant zone is deformed to a lesser extent, so the advantages of both SPH and FEM can be combined. SPH particles are used to reflect the development of cracks near the borehole wall, and the FEM is used to reflect the mechanical state during blasting in the area far away from the borehole. Johnson and Holmquist [20] combined the SPH method and the finite-element method to numerically simulate the high-speed collision problem and used the experimental results to verify the feasibility of the numerical simulation. The results of Gharehdashs et al. [25] can be applied to effectively simulate both compressive and tensile damage of rock subjected to blast loading by the coupled SPH-FEM method used in numerical simulation.

The basis of the SPH method is interpolation theory. Any macroscopic variable in SPH (such as density, pressure, and temperature) can be expressed as an integral interpolation using a set of values on a set of disordered points. The interaction of each particle is described by means of an interpolation function. The interpolation function gives the core estimation value of the quantity field at one point, and the conservation law of continuum dynamics is changed from the differential equation form to the integral form and then into the summation. In the SPH method, the mass point approximation function is defined as [26]

$$
f\left(x_{i}\right)=\sum_{j=1}^{N} \frac{m_{j}}{\rho_{j}} f\left(x_{j}\right) W\left(\left|x_{i}-x_{j}\right|, h\right) .
$$

In the formula, $m_{j}$ and $\rho_{j}$ are the mass and density of the particles, respectively. $W$ is the kernel function (interpolation kernel). 
The kernel function $W$ is defined using an auxiliary function $\theta$ :

$$
W(x, h)=\frac{1}{h(x)^{d}} \theta(x) .
$$

$d$ is the space dimension, $h$ is the smooth length, and the smooth length varies with time and space. $W(x, h)$ is the peak function, and the most common smooth kernel in SPH is the cubic B-spline.

$$
\theta(x)=C \times \begin{cases}1-\frac{3}{2} u^{2}+\frac{3}{4} u^{3}, & |u| \leq 1, \\ \frac{1}{4}(2-u)^{3}, & 1 \leq|u| \leq 2, \\ 0, & 2 \leq|u| .\end{cases}
$$

$C$ is the normalization constant, which is determined by the space dimension.

Mass conservation equation is as follows:

$$
\frac{d \rho}{d t}\left(x_{i}\right)=\sum_{j=1}^{N} m_{j}\left[v\left(x_{j}\right)-v\left(x_{i}\right)\right] A_{i j} .
$$

Momentum conservation equation is as follows:

$$
\frac{d v^{\alpha}}{d t}\left(x_{i}\right)=\sum_{j=1}^{N} m_{j}\left[\frac{\sigma^{\alpha, \beta}\left(x_{j}\right)}{\rho_{i}^{2}} A_{i j}-\frac{\sigma^{\alpha, \beta}\left(x_{i}\right)}{\rho_{j}^{2}} A_{j i}\right] \text {. }
$$

Energy conservation equation is as follows:

$$
\frac{d E}{d t}\left(x_{i}\right)=-\frac{P_{i}}{\rho_{i}^{2}} \sum_{j=1}^{N} m_{j}\left[v\left(x_{j}\right)-v\left(x_{i}\right)\right] A_{i j} .
$$

To realize the transfer of effective information such as stress and strain between SPH particles and FEM finiteelement grids, the key lies in how to define the coupling contact between the two. In this paper, the *CONTACT_TIED_NODES_TO_SURFACE keyword in LSDYNA software is used to cement the SPH particles and the FEM grid together (Figure 4). Through such a contact setting, the bonded particles will transfer the mechanical state transferred from other particles to the FEM mesh. The numerical calculation model of the SPH-FEM coupling algorithm is shown in Figure 5.

\subsection{Material Model}

2.3.1. Rock Material Model. The continuum constitutive model (JH model) proposed by Johnson et al. [20] describes the mechanical behaviour of brittle materials, such as strain rate effects and damage changes under impact loading. The mechanical properties of rock materials are described by the $\mathrm{JH}$ constitutive model, which can well simulate the large deformation, high strain rate, and high stress effects of the material. Therefore, the material is widely used in the numerical simulation of rock blasting in civil engineering.

The equivalent stress can be expressed as

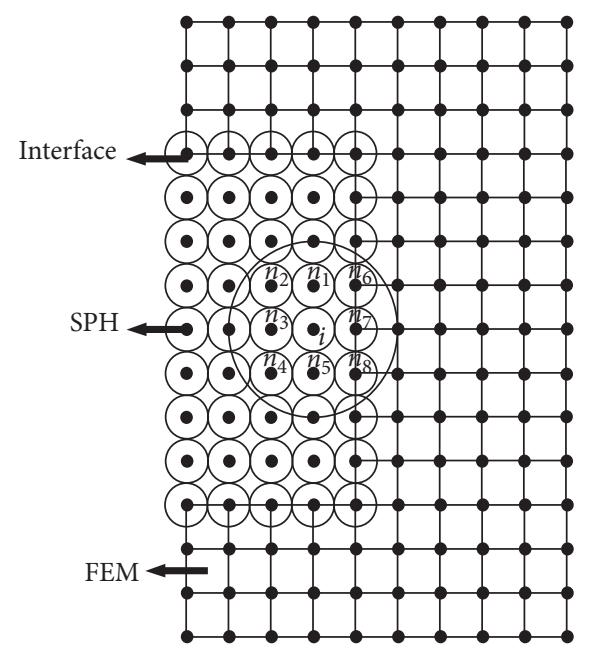

FIgUre 4: Contact face between SPH and FEM.

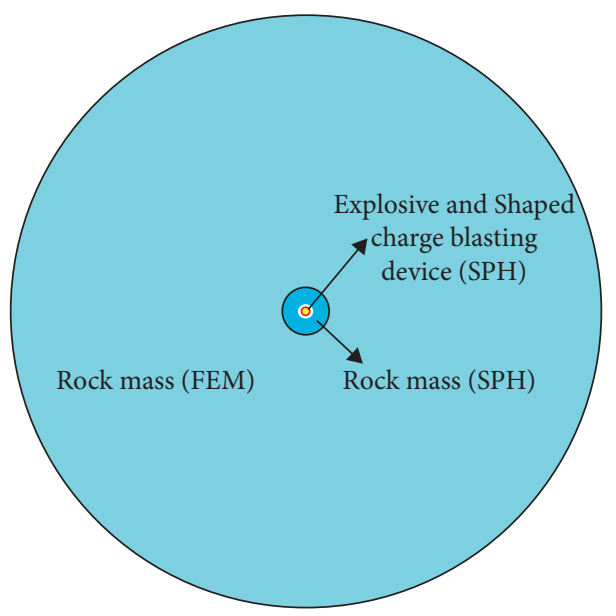

Figure 5: The numerical model used in the calculations.

$$
\sigma_{i}^{*}=A\left(P^{*}+T^{*}\right)^{N}\left(1+C \ln \dot{\varepsilon}^{*}\right) .
$$

The fully fractured strength is given as

$$
\sigma_{f}^{*}=B\left(P^{*}\right)^{M}\left(1+C \ln \dot{\varepsilon}^{*}\right) .
$$

The strength of damaged material is given as

$$
\sigma^{*}=\sigma_{i}^{*}-D\left(\sigma_{i}^{*}-\sigma_{f}^{*}\right)
$$

In the formula, $\sigma_{i}$ is the actual failure strength of the rock material. On normalizing the effective stress of the material, the effective stress of the completely fractured material, and the current effective stress expression, the following are obtained: $\sigma_{i}^{*}=\sigma_{i} / \sigma_{\mathrm{HEL}}, \quad \sigma_{f}^{*}=\sigma_{f} / \sigma_{\mathrm{HEL}}$, and $\sigma^{*}=\sigma / \sigma_{\mathrm{HEL}}$, where $\sigma_{\mathrm{HEL}}$ is the Hugoniot elastic limit; $P^{*}$ is the normalized hydrostatic pressure, $P^{*}=P / P_{\mathrm{HEL}}, P$ is the actual strength and $P_{\mathrm{HEL}}$ is the strength at the Hugoniot elastic limit; $T^{*}$ is the maximum tensile hydrostatic pressure that the rock can withstand, $T^{*}=T / P_{\mathrm{HEL}}, T$ is the maximum tensile; $D$ is the damage factor, with a value between 0 and 1 ; $A, C$, and $N$ are the rock material constant; $B$ and $M$ are the 
residual strength of the rock material; $\sigma$ is the effective stress, and its general expression formula is

$$
\sigma=\left\{\frac{\left(\sigma_{x}-\sigma_{y}\right)^{2}+\left(\sigma_{x}-\sigma_{z}\right)^{2}+\left(\sigma_{y}-\sigma_{z}\right)^{2}+6\left(\tau_{x y}^{2}+\tau_{x z}^{2}+\tau_{y z}^{2}\right)}{2}\right\}^{1 / 2} .
$$

$\sigma_{x}, \sigma_{y}$, and $\sigma_{z}$ are three normal stress components; $\tau_{x y}$, $\tau_{x z}$, and $\tau_{y z}$ are three shear stress components. The strain rate of the $\mathrm{JH}$ model is expressed by the dynamic intensity factor (DIF):

$$
\mathrm{DIF}=1+C \ln \dot{\varepsilon}^{*}
$$

In the formula, $C$ is a constant, normalized strain rate: $\dot{\varepsilon}^{*}=\dot{\varepsilon} / \dot{\varepsilon}_{0}, \dot{\varepsilon}$ is the actual strain rate of the rock, and $\dot{\varepsilon}_{0}=$ $1.0 s^{-1}$ is the reference strain rate and is similar to the equivalent stress. The actual equivalent strain rate can be expressed as

$$
\dot{\varepsilon}=\sqrt{\frac{2}{9}\left[\left(\dot{\varepsilon}_{x}-\dot{\varepsilon}_{y}\right)^{2}+\left(\dot{\varepsilon}_{y}-\dot{\varepsilon}_{z}\right)^{2}+\left(\dot{\varepsilon}_{z}-\dot{\varepsilon}_{x}\right)^{2}+\frac{3}{2}\left(\dot{\gamma}_{x y}^{2}+\dot{\gamma}_{y z}^{2}+\dot{\gamma}_{z x}^{2}\right)\right]} .
$$

The JH material constitutive model is divided into three parts: the polynomial state equation is described in Figure 6(a), the strength model is described in Figure 6(b), and the damage model is described in Figure 6(c). The polynomial state equation can be divided into two parts:

$$
P= \begin{cases}K_{1} \mu+K_{2} \mu^{2}+K_{3} \mu^{3}+\Delta P & \mu<0 \\ K_{1} \mu & \mu>0\end{cases}
$$

where $K_{1}, K_{2}$, and $K_{3}$ are material constants of the state equation, $P$ is the actual hydrostatic pressure, $\mu$ is the volumetric strain, $\mu=\rho / \rho_{0}-1, \rho$ is the current density of the material, $\rho_{0}$ is the initial material density, and $\Delta P$ is the increment of the additional pressure. When the damage starts to accumulate, the additional pressure increase is accompanied by the appearance of the volume expansion effect (the volume increases while the body strain increases). The pressure increase mainly comes from energy changes, and its value range is change between $\Delta P=0$ (i.e., when $D=0$ ) and $\Delta P=\Delta P_{\max } \max$ (when $D=1$ ).

The damage factor $D$ in the JH material model can be expressed as

$$
D=\sum \frac{\Delta \varepsilon_{p}}{\varepsilon_{p}^{f}}
$$

where $\Delta \varepsilon_{p}$ is the finite plastic strain integral in a single cycle and $\varepsilon_{p}^{f}=f(P)$ is the equivalent fracture plastic strain of the material.

$$
\varepsilon_{p}^{f}=D_{1}\left(P^{*}+T^{*}\right)^{D_{2}},
$$

where $D_{1}$ and $D_{2}$ are the rock damage degree functions introduced in the $\mathrm{JH}$ model. The parameters of the $\mathrm{JH}$ constitutive model are shown in Table 1 [21].
2.3.2. Explosive and Shaped Tube Material Model. The explosive used in this paper is a DYNO cord made of PETNs [21]. The explosive constitutive model adopts constitutive model No. 8 in LS-DYNA ${ }^{*}$ MAT_HIGH_EXPLOSIVE_BURN, combined with the JWL state equation. The model can comprehensively consider factors such as aperture, hole depth, and explosive properties and can more truly reflect the actual collision process of explosives. The relationship between pressure and specific volume is as follows:

$$
P=A\left(1-\frac{\omega}{R_{1} V}\right) e^{-R_{1} V}+B\left(1-\frac{\omega}{R_{2} V}\right) e^{-R_{2} V}+\frac{\omega E_{0}}{V} \varepsilon_{p}^{f},
$$

where $A, B, R_{1}, R_{2}$, and $\omega$ are the material constants; $P$ is the pressure; $V$ is the relative volume; and $E_{0}$ is the initial specific internal energy. The specific parameters are shown in Table 2.

Since the condenser tube used in the actual project is generally a PVC, in this order value simulation, the plastic follow-up model (MAT_PLASTIC_KINEMATIC) is selected to represent the constitutive equation of the PVC material, and the strain-rate-related parameters are used to represent the stress state; namely, $\sigma_{Y}$ is the yield stress; $\sigma_{0}$ is the initial stress; $C$ and $P$ are the Cowper-Symonds strain rate parameters; $\varepsilon_{p}^{e f f}$ is the effective plastic strain; and $E_{p}$ is the plastic hardening modulus. The specific parameters of the PVC pipe material are shown in Table 3 [27].

\section{Numerical Simulations}

3.1. Numerical Calculation Model Verification. The distribution of cracks near the rock mass obtained by the 


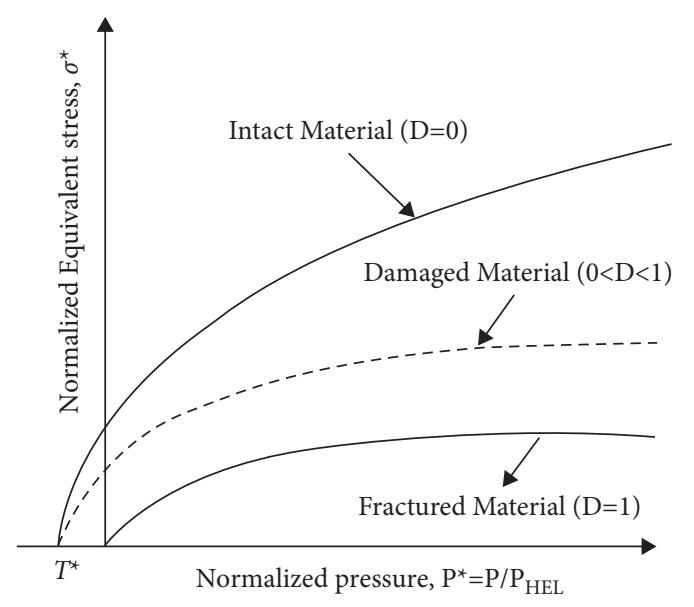

(a)

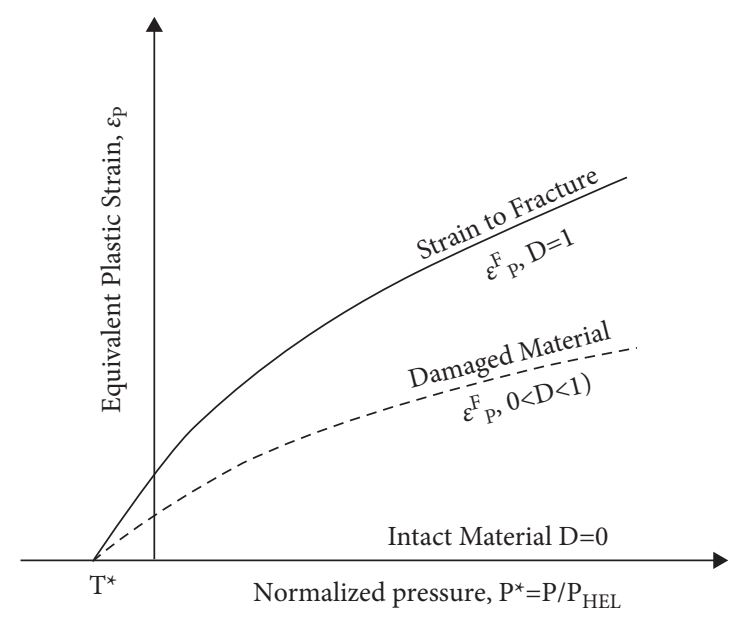

(b)

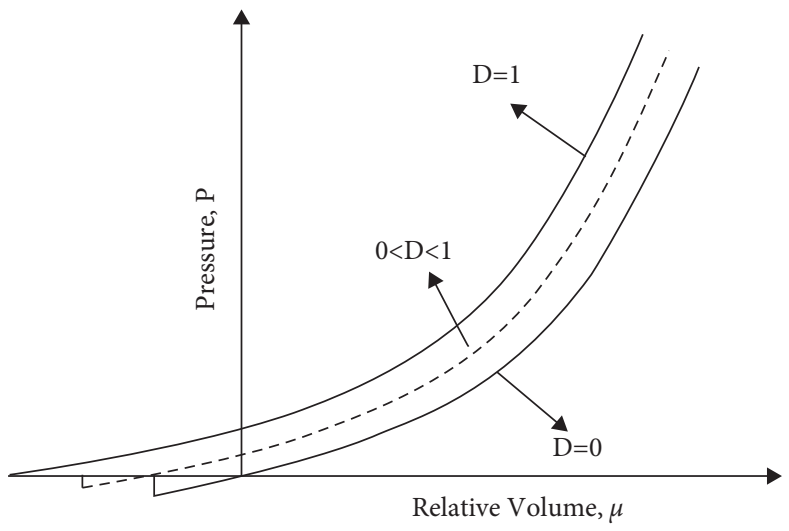

(c)

FIGURE 6: Schematic illustration of the JH material model: (a) strength model, (b) damage model, and (c) pressure-volume relations.

TABle 1: Parameters of JH constitutive model [21].

\begin{tabular}{|c|c|c|c|}
\hline Parameters & & Unit & Value \\
\hline \multicolumn{4}{|l|}{ Equation of state } \\
\hline Reference density & $\rho_{0}$ & $\mathrm{~g} / \mathrm{cm}^{3}$ & 2.66 \\
\hline Bulk modulus & $K_{1}$ & $\mathrm{GPa}$ & 25.70 \\
\hline Polynomial EOS constant & $K_{2}$ & $\mathrm{GPa}$ & -4500.00 \\
\hline Polynomial EOS constant & $K_{3}$ & $\mathrm{GPa}$ & 300000.00 \\
\hline \multicolumn{4}{|l|}{ Johnson-Holmquist strength model } \\
\hline Shear modulus & G & $\mathrm{GPa}$ & 21.90 \\
\hline Hugoniot elastic limit & HEL & $\mathrm{GPa}$ & 4.50 \\
\hline Intact strength constant & $A$ & & 0.76 \\
\hline Intact strength exponent & $N$ & & 0.62 \\
\hline Strain rate constant & C & & 0.005 \\
\hline Fractured strength constant & $B$ & & 0.250 \\
\hline Fractured strength exponent & $M$ & & 0.62 \\
\hline Max. fractured strength ratio & $\sigma_{F \mathrm{Max}}^{*}$ & & 0.25 \\
\hline \multicolumn{4}{|l|}{ Johnson-Holmquist failure model } \\
\hline Hydrotensile limit & HTL & $\mathrm{MPa}$ & -54.00 \\
\hline Damage constant & $D_{1}$ & & 0.005 \\
\hline Damage constant & $D_{2}$ & & 0.70 \\
\hline Bulking constant & $\beta$ & & 0.50 \\
\hline Type of tensile failure & & & Hydro \\
\hline
\end{tabular}


TABLE 2: Parameters of explosive [21].

\begin{tabular}{lcccccccc}
\hline Explosive density $\left(\mathrm{g} / \mathrm{cm}^{3}\right)$ & Velocity of detonation $(\mathrm{m} / \mathrm{s})$ & CJ pressure $(\mathrm{GPa})$ & A $(\mathrm{GPa})$ & B $(\mathrm{GPa})$ & $R_{1}$ & $R_{2}$ & $\omega$ & $E_{0}(\mathrm{GPa})$ \\
\hline 1.32 & 6690 & 16.0 & 586 & 21.6 & 5.81 & 1.17 & 0.28 & 7.38 \\
\hline
\end{tabular}

Table 3: Parameters of PVC [27].

\begin{tabular}{lcccc}
\hline$\rho\left(\mathrm{g} / \mathrm{cm}^{3}\right)$ & $\mathrm{E}(\mathrm{GPa})$ & $E_{\tan }(\mathrm{GPa})$ & $\sigma_{\mathrm{c}}(\mathrm{MPa})$ & $\mu$ \\
\hline 1.43 & 3.59 & 1.08 & 61.7 & 0.32 \\
\hline
\end{tabular}

numerical simulation of a single borehole is shown in Figure 7(a). The impact created the crushing zone and crack zone near the surrounding rock of the borehole. In the experimental result of Banadaki and Mohanty [21], as shown in Figure 7(b), Banadaki and Mohanty [21] used digital photography to count the area of the crushing zone and crack zone near the borehole. The analysis results are as follows. The crushing zone is approximately 5-6 times the borehole radius, and the crack zone is $20-22$ times the borehole radius. In the numerical simulation of this paper, the borehole radius is $3 \mathrm{~cm}$, as shown in Figure $7(\mathrm{a})$. The radius of the crushing zone is approximately $16 \mathrm{~cm}$, and the crushing zone is 5-6 times the radius of the borehole; the radius of the crack zone is approximately $58 \mathrm{~cm}$, and the radius of the crack zone is approximately 19 times the radius of the borehole, which is roughly the same as the experimental results of Banadaki and Mohanty [21] in the macroscopic view. At the same time, Banadaki and Mohanty [21] also used numerical simulation to reproduce the crack propagation process in the experiment and made certain corrections and verifications to the parameters of the granite $\mathrm{JH}$ model. The numerical simulation results obtained are in good agreement with the experimental results, which fully shows that the model and parameters of the numerical simulation adopted in this paper are reasonable.

\subsection{Results and Discussion}

3.2.1. Comparative Analysis of Single-Hole Ordinary Smooth Blasting and Shaped Charge Blasting. The arrangement of measuring points for ordinary blasting and directional blasting of shaped charge packs is shown in Figure 8. After the blasting of ordinary smooth blasting explosives, the damage evolution law is shown in Figures 9(a)-9(c). For the ordinary blasting structure, after the explosive is blasted, the explosive particles will spread around, as shown in Figure 9(a). After the blasting time reaches $7 \mu \mathrm{s}$, the explosive wave makes the explosive particles contact the rock particles and causes damage around the borehole wall. After the blasting time reaches $250 \mu \mathrm{s}$, as shown in Figure 9(b), the crushing area and cracked area are produced on the surrounding rock. The crushing zone is mainly concentrated in the area near the borehole, and the cracks in the crack zone show a development trend of expanding to the surroundings. After the time reaches $400 \mu \mathrm{s}$, the crack propagation activity stops, and the length of the cracks propagating in all directions is different and shows certain randomness.
However, because the rock is mainly subjected to tensile stress to produce damage, the main cracks are still concentrated in the $0^{\circ}, 45^{\circ}$, and $90^{\circ}$ directions.

For the shaped charge structure, the explosive particles will spread around after the explosive is detonated. The PVC particles of the shaped charge tube in the shaped charge direction will be squeezed so that a shaped energy jet is formed in the shaped charge direction. The nonshaped charge directional PVC shell has a certain hindering effect on the diffusion of explosive particles and delays the time for explosives to impact the borehole. As shown in Figure 9(d), when it reaches $10 \mu \mathrm{s}$ after initiation, the energy-concentrating jet formed in the energy-concentrating direction first contacts the borehole, which has a certain corrosive effect on the rock. For the nonenergy-concentrating direction, the shell affects the explosive particles. The obstructive effect of the shell caused the damage to nonenergy-concentrating borehole to lag behind, so that the overall blasting damage reached a kind of "notch" blasting effect. After the blasting time reaches $200 \mu \mathrm{s}$, cracks in all directions around the borehole develop, and the cracks in the shaped charge direction extend longer; at the same time, the preliminarily shaped charge orientation effect is achieved. The crack development speed in the nonshaped charge direction gradually stagnates. After the time reaches $400 \mu$ s, the expansion of the overall burst pattern also tends to stop. Because of the secondary action of the detonation wave, the cracks in the shaped charge direction continue to expand within $200 \mu$ s to $400 \mu$ s until the overall blasting activity ends. The cracks in the shaped charge direction are much longer than the cracks in other directions, so the shaped charge effect is obvious.

Comparing the directional blasting of the shaped charge pack and ordinary smooth blasting, in the early stage of the blasting action, since there is no need to perform a certain impact on the energy tube and shell, ordinary smooth blasting explosive particles will quickly and synchronously impact the borehole wall. The explosive particles of the energy charge blasting will form a shaped energy jet that will corrode the borehole in the direction of energy accumulation. Particles in other directions will lag behind due to the obstruction and reflection of the shell. Certain stress concentration phenomena in the borehole wall are first eroded so that the cracks in the energy direction will continue to expand under the continuous action of subsequent stress waves. After the blasting time reaches $200 \mu$ s, both ordinary smooth blasting and shaped charge blasting cause certain damage to the surrounding rock near the borehole. Because 


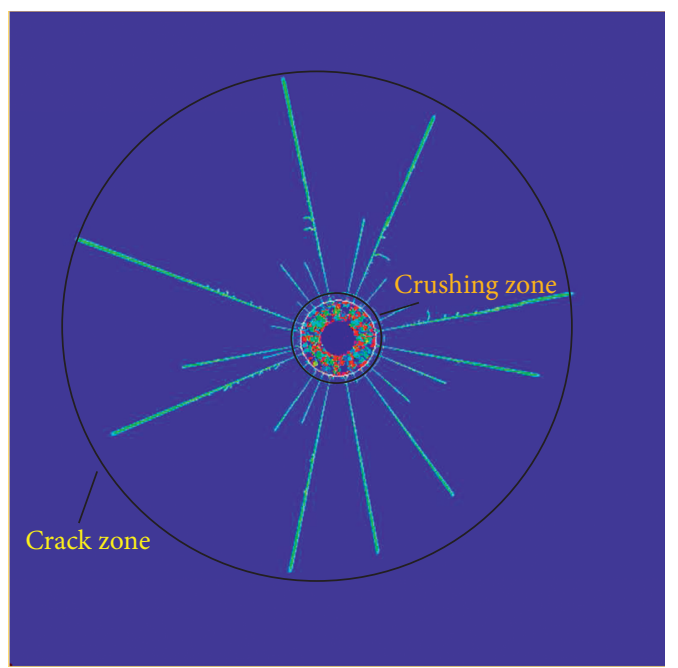

(a)

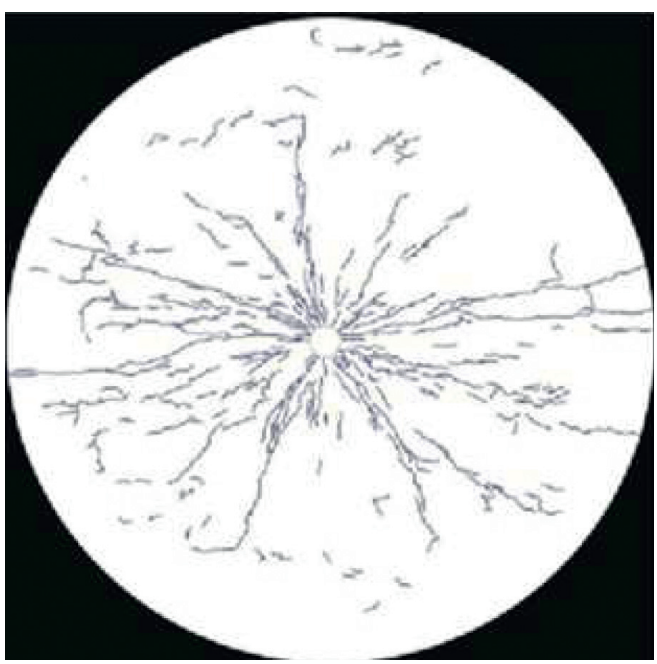

(b)

FIGURE 7: Comparison between the numerical simulation and the experimental result by Banadaki and Mohanty [21]. (a) Crack pattern of numerical model. (b) Crack pattern of rock experiment (Banadaki and Mohanty 2010) [21].

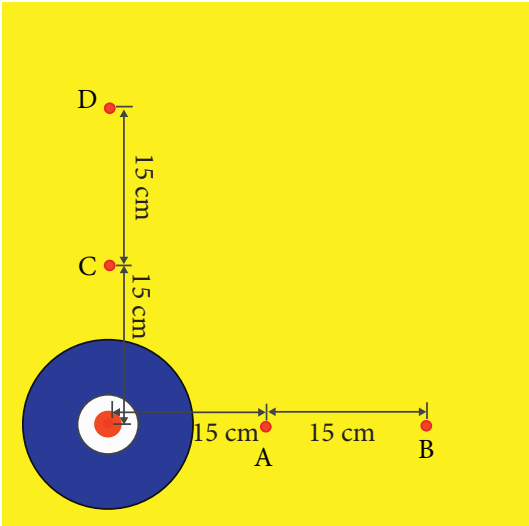

(a)

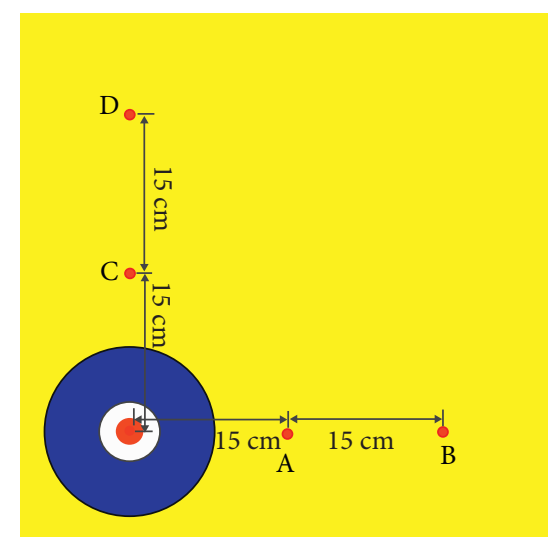

(b)

FIgURE 8: Key points on single-hole loading. (a) Single-hole loading. (b) Double-hole loading.

the amount of explosives in the ordinary cartridge is nearly $1 / 3$ more than that of the shaped cartridge, ordinary smooth blasting has a wider damage surface to the surrounding rock, and the crack is longer. The shaped charge effect of the shaped charge cartridge blasting is initially formed, and the crack in the shaped charge direction is longer. After $400 \mu \mathrm{s}$, the activities of ordinary smooth blasting and shaped charge blasting stopped. In the later blasting stage, all directional cracks of ordinary smooth blasting developed to a certain extent. The overall blasting development trend and blasting profile are the same as before. For shaped charge blasting, under the secondary action of the detonation wave, cracks in the shaped charge direction are further developed due to the stress concentration, forming an obviously shaped charge effect. In contrast, crack propagation in the nonshaped charge direction basically stagnates and reduces damage to the surrounding rock in the nonshaped charge direction. The four measuring points A, B, C, and D are shown in Figure 8 for ordinary smooth blasting and shaped charge blasting.
The stress wave spreading process under the structure of single-hole-shaped energy blasting is shown in Figure 10. The circumferential stress of the four points is shown in Figure 11, and Figure 11(a) shows ordinary smooth blasting. The circumferential stress at four points A, B, C, and D can be seen in Figure 11. After the blasting time reaches $47 \mu \mathrm{s}$, the stress at points A and C $15 \mathrm{~cm}$ from the blasting centre will reach the highest peak and then continue to decay; after the time reaches $94 \mu \mathrm{s}$, the stress at points B and D $30 \mathrm{~cm}$ from the blasting centre will reach the highest peak, and then the stress wave decays continuously. From Figure 11, we can observe that the stress development of the two Gauss points in the horizontal and vertical directions is roughly similar. The detonation wave is scattered in ordinary smooth blasting. Figure 11(b) shows the circumferential stress at four points $\mathrm{A}, \mathrm{B}, \mathrm{C}$, and $\mathrm{D}$ under shaped charge blasting, where points $A$ and $B$ are arranged in the transverse direction of energy accumulation and points $\mathrm{C}$ and $\mathrm{D}$ are arranged in the longitudinal direction of nonenergy 


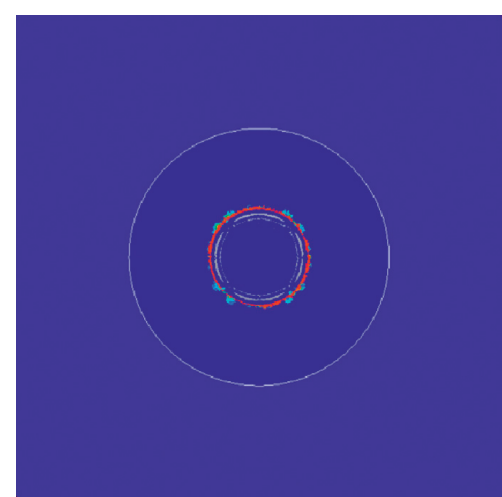

(a)

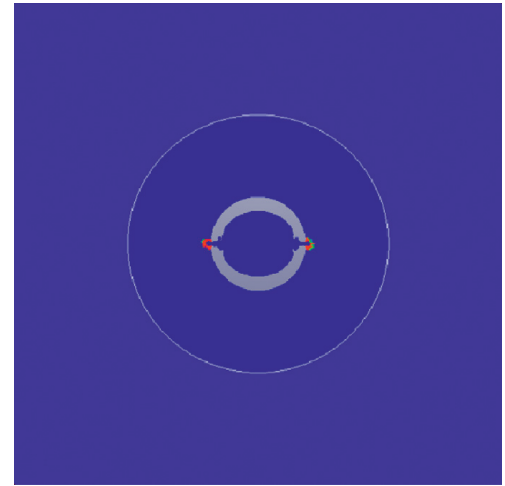

(d)

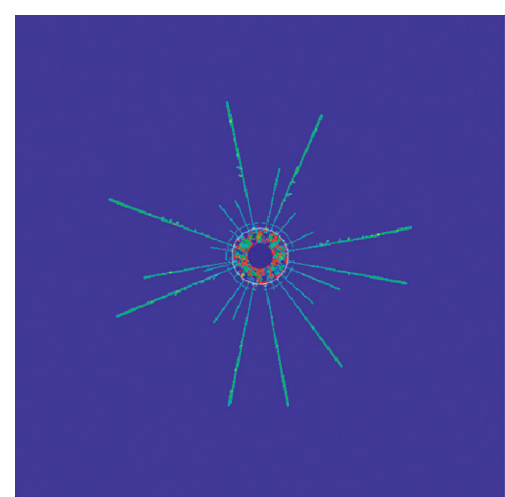

(b)

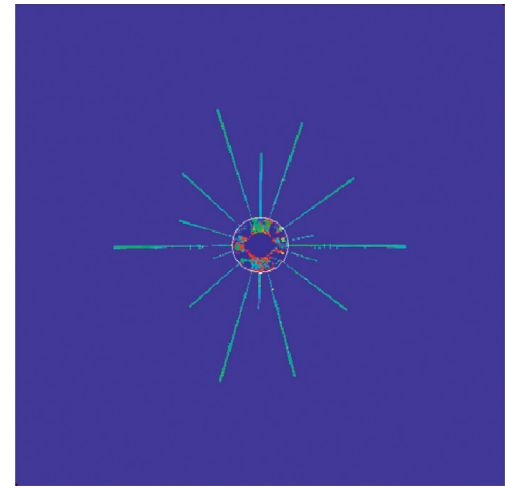

(e)

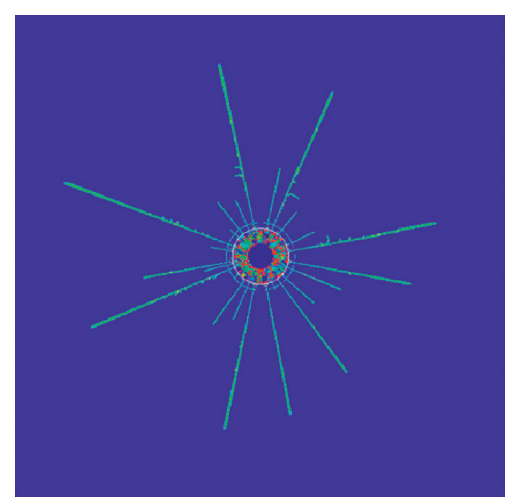

(c)

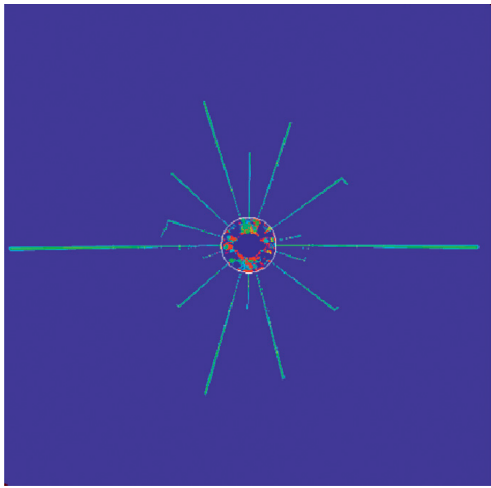

(f)

Figure 9: Damage propagation process under single-hole load. $(a-c)$ Ordinary blasting. (d-f) Shaped blasting.

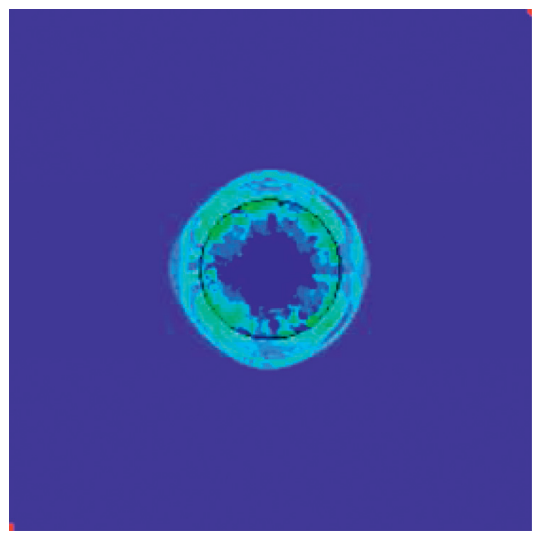

(a)

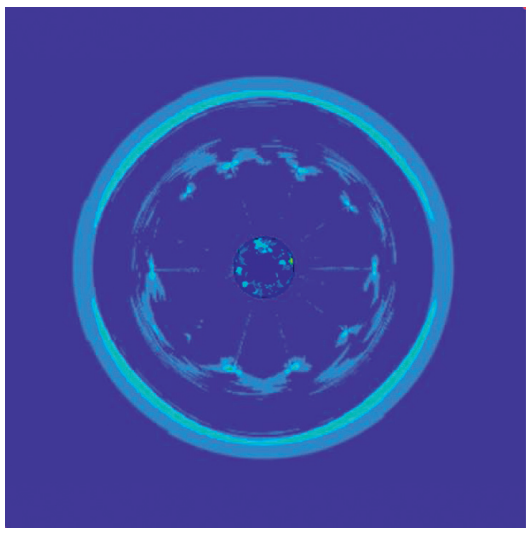

(b)

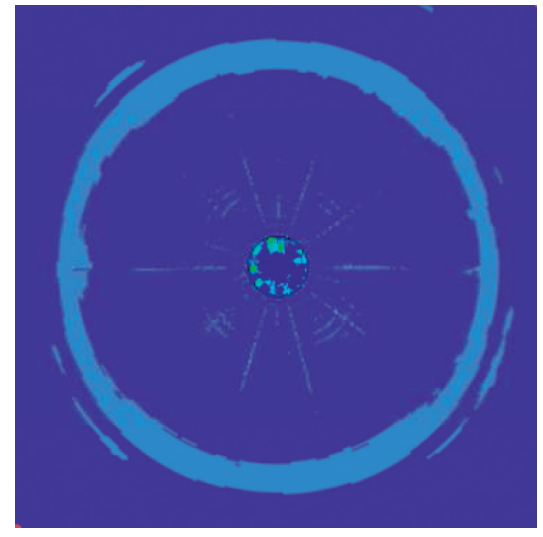

(c)

FIGURE 10: Stress wave spreading process under single-hole loading.

accumulation. Figure 11 shows that the detonation wave first reaches point $A 15 \mathrm{~cm}$ from the centre of the borehole after the detonation of the energy-concentrating charge at $54 \mu \mathrm{s}$, and the detonation stress arrives at a stress peak, while the stress development at point $\mathrm{B}$ in the nonenergy-concentrating direction falls behind the stress at point A. At the same time, the stress peak at point $B$ is also lower than the stress peak at point $\mathrm{A}$. The reason is that, after the blasting of the accumulating charge, the jet in the accumulating direction first contacts the hole wall, so the stress propagation speed in the accumulating direction is slightly faster than that in the nonaccumulating direction. Comparing diagrams in Figure 11(a) and Figure 11(b), the propagation time of the stress wave of ordinary smooth blasting is earlier than that of energy-forming charge blasting. This is because ordinary smooth blasting does not require a crushing effect on the energy-generating tube. At the same time, the amount of ordinary medicine packaging is also larger than the 


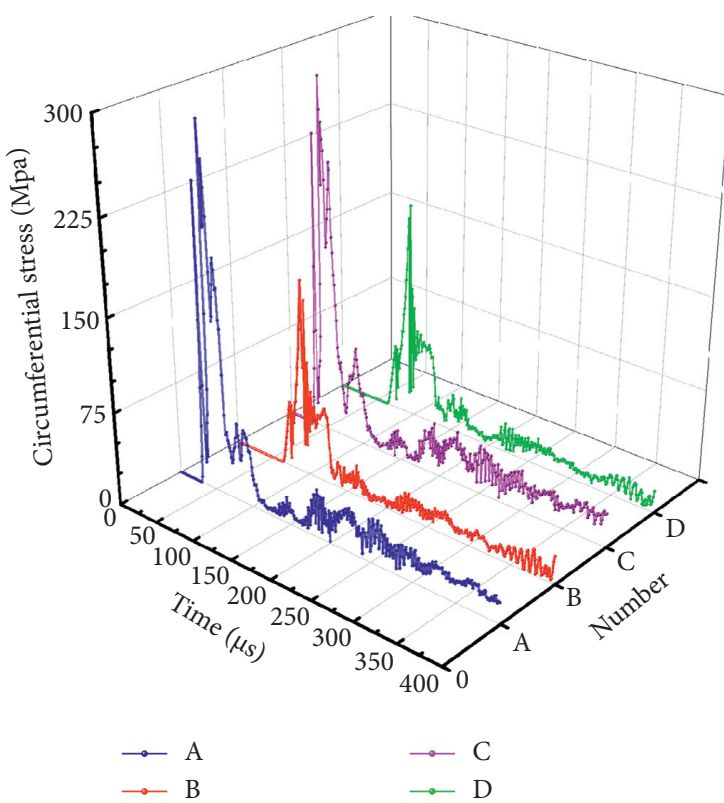

(a)

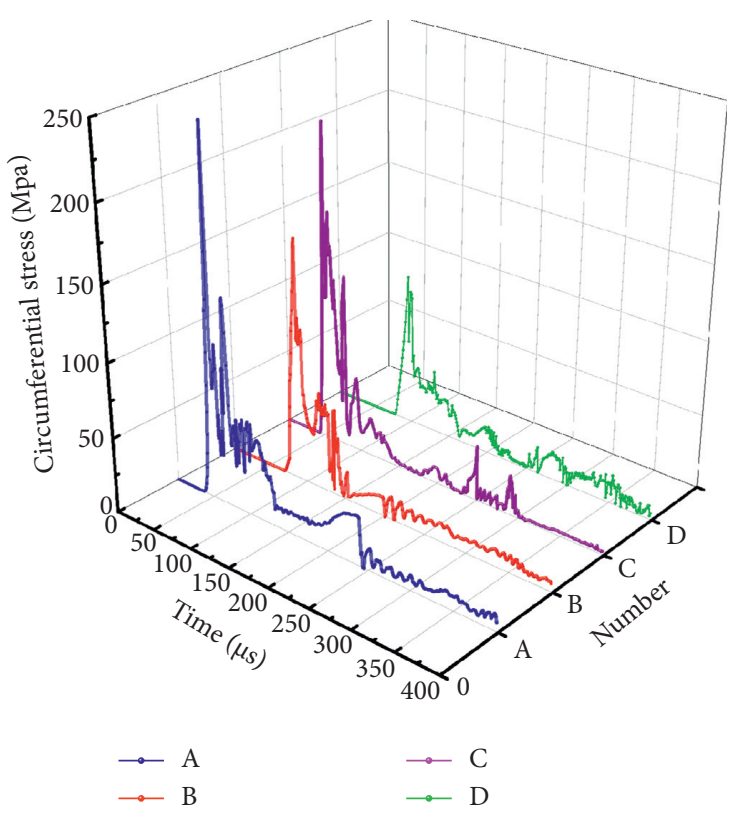

(b)

Figure 11: Stress diagram under single-hole load. (a) Ordinary smooth blasting. (b) Shaped blasting.

shaped charge bag, which also causes the stress wave peak generated by ordinary blasting to be greater than the blasting stress wave peak of the shaped charge bag.

\subsubsection{Establishment of the Three-Dimensional Single-Hole} Numerical Simulation Model. A model test block model of $80 * 80 * 80 \mathrm{~cm}$ was built in LS-DYNA, where the borehole diameter is $42 \mathrm{~mm}$ and the depth of the borehole is $20 \mathrm{~cm}$. The 3D calculation model and the experimental test block model are shown in Figures 12 and 13.

The results of the numerical simulation are analyzed. It can be seen from Figure 14 that when the time after blasting reaches $100 \mu \mathrm{s}$, the shock wave generated by the explosives will rapidly impact the model test block, in which the normal blast shock wave impacts the wall of the shell hole and later develops around the test block, producing a huge damage zone in the preblast period, while the energy in the early stage of polyenergy blasting is mainly concentrated in the formation of shaped charge jets. Thus, damage to the specimen is not obvious. When the blasting time reached $300 \mu$ s, comparing the normal blast and the shaped blast, the normal blast crack developed in all directions, and the crack extension direction was largely concentrated in the $0^{\circ}, 45^{\circ}$, and $90^{\circ}$ directions of the test block. The blast wave had a tensioning effect on the model block, which was the same trend as the previous results. In contrast, the crack development trend was similar in the gather energy and nongather energy directions. The trend of crack development is similar; while the cracks produced by the gather energy blasting are mainly concentrated in the gather energy direction, the cracks in the nongather energy direction are inhibited from developing, producing an obvious gather energy directional blasting effect. When the time reaches
$1000 \mu \mathrm{s}$, the energy of the explosive is dispersed in all directions, and the development of cracks stops after ordinary blasting. According to the principle of energy conservation, after the energy required for the development of cracks in other directions is reduced, it will further enhance the development of cracks in the gather energy direction and the reduction of energy required for the development of cracks in other directions. Finally, it leads to the crack extension of the specimen mode and is eventually destroyed.

\subsubsection{Analysis of the Double-Hole Blasting Effect of the} Directional Blasting of Shaped Charge Packs. A model with a double-hole drill spacing of $80 \mathrm{~cm}$ was used for analysis. In the early stage of the explosion, the directional blasting effect of the double-hole-shaped charge pack is the same as the single-hole blasting effect. The explosive particles will have a crushing effect on the shaped energy tube so that the shaped energy tube will form a shaped energy jet that rapidly impacts the wall of the corroded hole and creates a groove similar to the " $V$ " shape. The groove plays a role in guiding the development and formation of subsequent cracks. In the numerical simulation in this paper, when the time reaches $50 \mu \mathrm{s}$, as shown in Figure 15(a), the double-hole blasting effect still acts independently, and the development speed of cracks in the energy-concentrating direction is slightly faster than that in the nonenergy-concentrating direction. When the time after blasting reaches $150 \mu \mathrm{s}$, as shown in Figure 15(b), the stress waves between the holes are superimposed on each other so that the cracks between the double holes develop faster, and the evolution process of the cracks between the holes has a certain direction. After reaching $200 \mu \mathrm{s}$, as shown in Figure 15, the length of the cracks between the holes is significantly longer than that of 


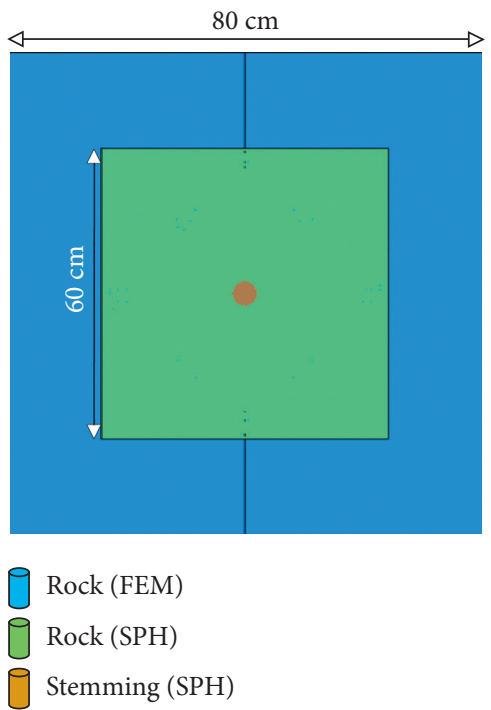

Figure 12: The 3D calculation model.

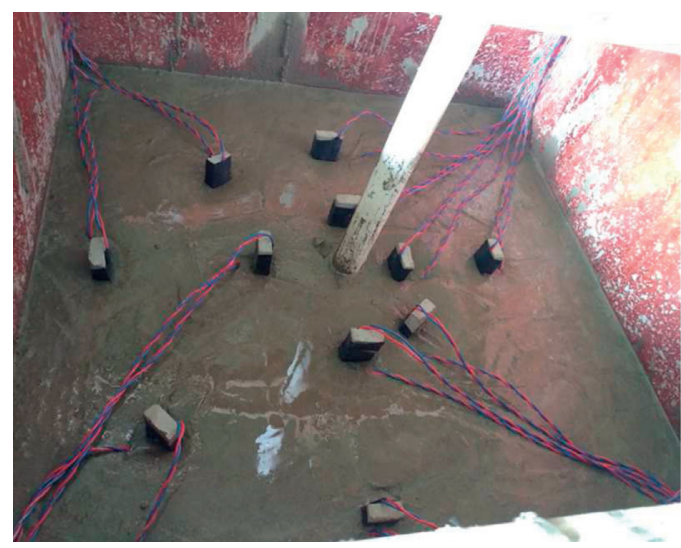

Figure 13: The experimental test block model.

the cracks in other directions. After the time reaches $220 \mu$ s, as shown in Figure 15(d), under the superimposition of the stress wave, concentrated stress is formed along the centerline of the double hole so that square damage is formed between the cracks connected on both sides of the doublehole area, and the axial crack between the double holes is perforated. To further understand the propagation process of the stress wave in the surrounding rock under the doublehole load, as shown in Figure 16, five measuring points are taken between the double holes, and the stress data of each measuring point are derived through LS-DYNA software. It can be seen from Figure 17 that the stress waveforms of the measuring points that are symmetric about the central axis between the two boreholes are roughly the same, the stress peak of the measuring point closer to the borehole comes earlier, and the stress magnitude of the stress wave peak is also larger. With increasing distance, the size of the stress wave is continuously reduced. It can be seen from Figure 17 that when the distance from the borehole reaches $25 \mathrm{~cm}$, the peak stress of the stress wave is obviously less than the peak stress of the stress wave at $10 \mathrm{~cm}$. However, the stress wave peak at $40 \mathrm{~cm}$ of the measuring point is larger than that at
$25 \mathrm{~cm}$. This is because the superposition of stress waves under the load of the double holes causes the stress waves near the central axis of the two boreholes to become larger, thus leading to the extension of the crack.

3.2.4. Expansion of the Blasting Pattern of the Shaped Charge under Different Drilling Distances. For the investigation of the expansion process of the double-hole blasting rupture under different drilling distances, the parameters of the shaped charge blasting hole spacing were optimized. The cracks from $80 \sim 140 \mathrm{~cm}$ double holes finally evolved. The explosives inside the two boreholes are blasted at the same time. Table 4 shows the structural parameters adopted by the six numerical simulations.

It can be found from Figure 18 that when the distance between the holes is $80 \sim 130 \mathrm{~cm}$, the axial cracks between the two holes are developed to a certain extent; also, the cracks in all directions between the double holes are developed under the superposition of stress waves. The extension of the two holes and the direction of extension have a certain tendency (extending to the direction of another 


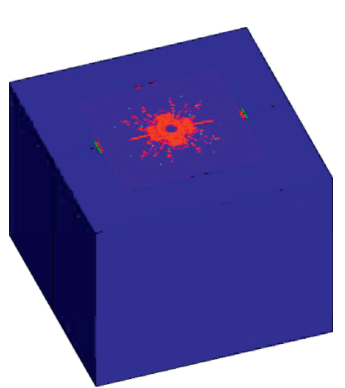

$100 \mu \mathrm{s}$

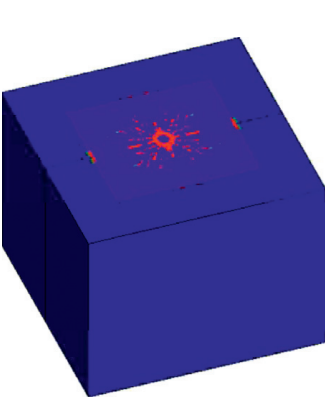

$100 \mu \mathrm{s}$

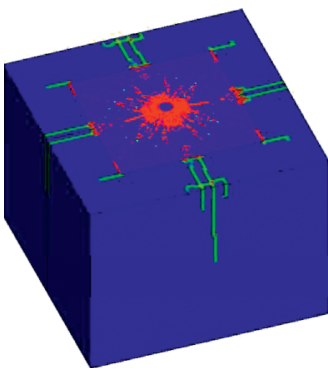

$300 \mu \mathrm{s}$

(a)

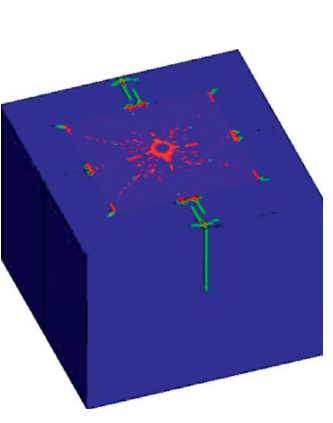

$300 \mu s$

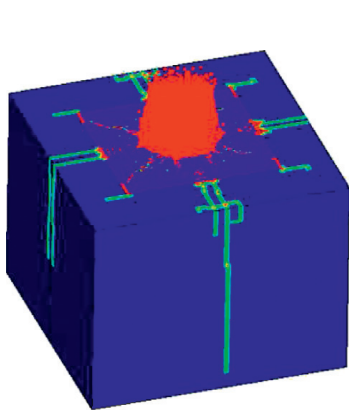

$1000 \mu \mathrm{s}$

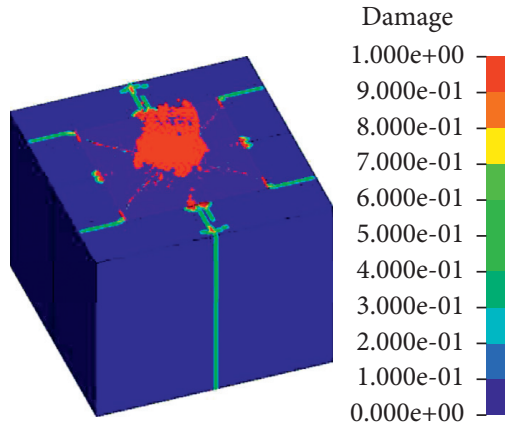

$1000 \mu \mathrm{s}$

Damage

$1.000 \mathrm{e}+00$ $9.000 \mathrm{e}-01$ $8.000 \mathrm{e}-01$ $7.000 \mathrm{e}-01$ $6.000 \mathrm{e}-01$ $5.000 \mathrm{e}-01$ $4.000 \mathrm{e}-01$ $3.000 \mathrm{e}-01$ $2.000 \mathrm{e}-01$ $1.000 \mathrm{e}-01$ $0.000 \mathrm{e}+00$

(b)

FIGURE 14: 3D damage map of the specimen model: (a) ordinary charge and (b) shaped charge.

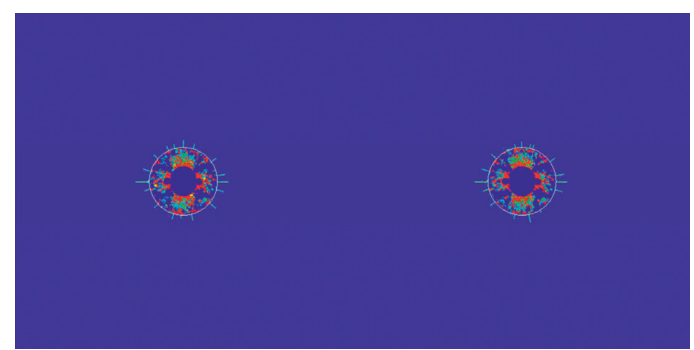

(a)

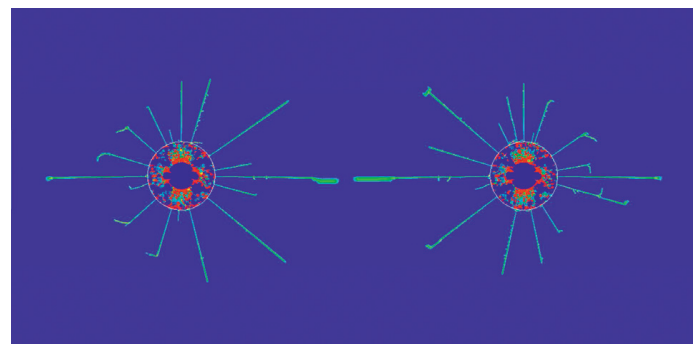

(c)

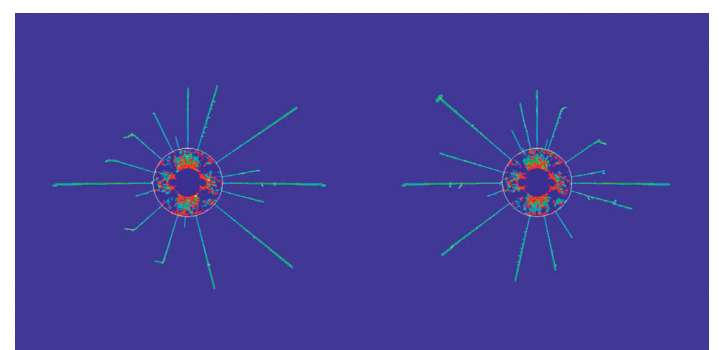

(b)

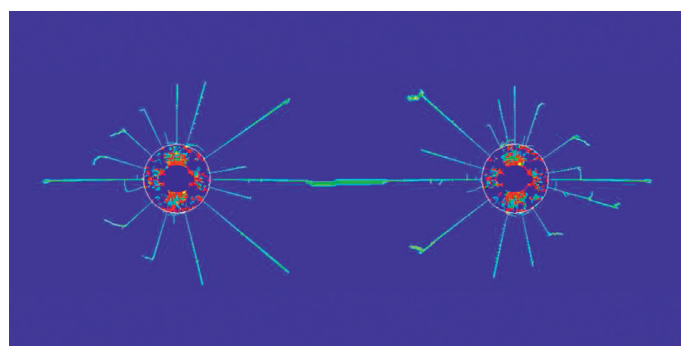

(d)

FIGURE 15: Damage propagation process under double-hole load.

hole). The superposition of stress between holes will be weakened as the spacing between holes increases. When the distance between two holes reaches $120 \mathrm{~cm}, 130 \mathrm{~cm}$ later, the axial cracks between the double holes cannot form a coherent damage zone.
With the increase in the distance between the two holes, the axial cracks between the two holes (the crack on the right of the left hole and the crack on the left of the right hole) show a trend of increasing first and then decreasing. When the aperture spacing is between 80 and $110 \mathrm{~cm}$, the cracks 


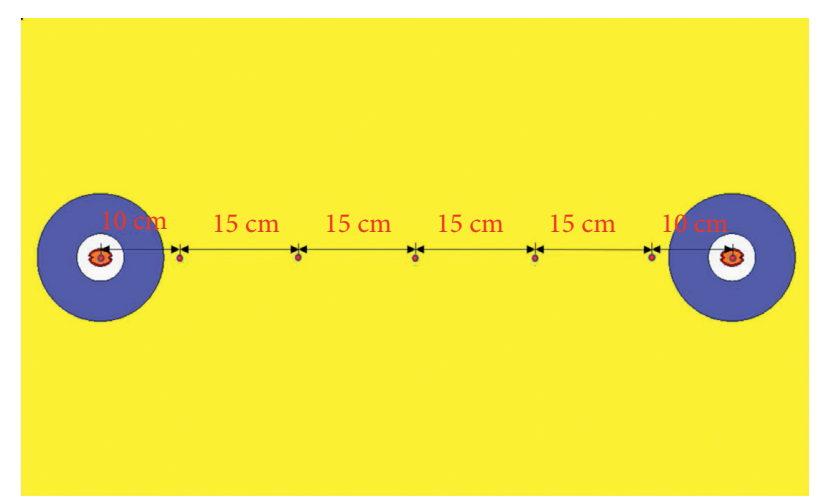

FIgURE 16: Key points location on double-hole loading.

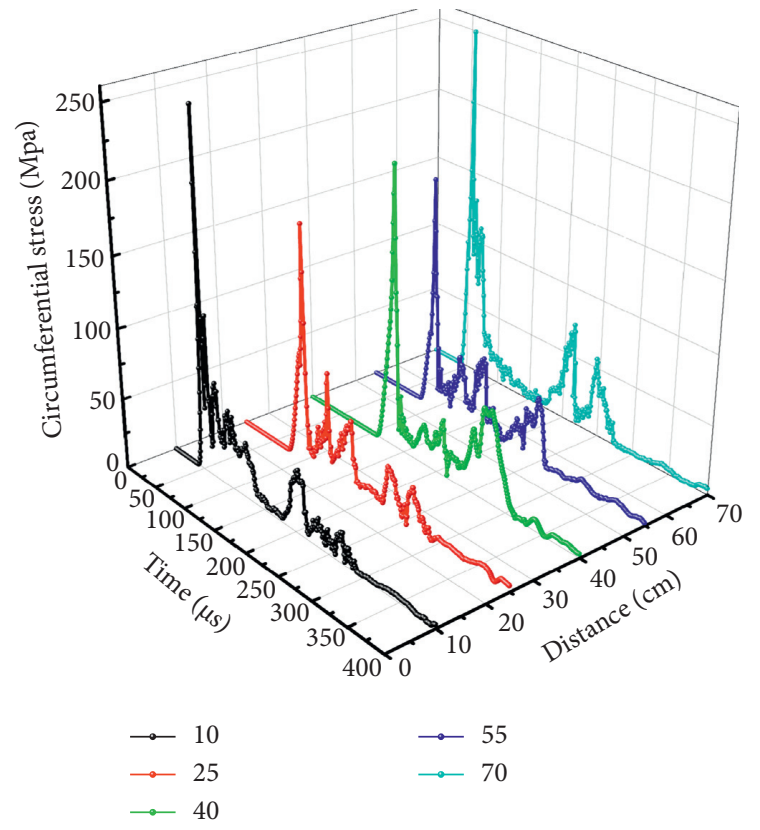

Figure 17: Stress diagram under double-hole loading.

TABLE 4: Parameters of the test.

\begin{tabular}{lcc}
\hline Test & Borehole diameter $(\mathrm{cm})$ & Borehole spacing $(\mathrm{cm})$ \\
\hline 1 & 6 & 80 \\
2 & 6 & 90 \\
3 & 6 & 100 \\
4 & 6 & 110 \\
5 & 6 & 120 \\
6 & 6 & 130 \\
\hline
\end{tabular}

between the double holes show an overall increasing trend, but the growth rate of the cracks between the two holes is random. When the double-hole spacing reaches $110 \mathrm{~cm}$, the length of the middle crack reaches the maximum, and the total length of the cracks between the double holes reaches $110 \mathrm{~cm}$, which forms a crack penetration zone. After the distance between the holes is greater than $110 \mathrm{~cm}$, the axial crack length is continuously reduced, and the change trend and rate of the double holes are the same, which indicates that the superposition of stress waves is constantly weakening. When the distance between holes reaches $140 \mathrm{~cm}$, the axial cracks between the two holes are almost the same as the cracks in the other two directions. According to Figure 19, when the distance between holes reaches $140 \mathrm{~cm}$, the superposition effect of the stress wave produced by double-hole blasting is very small.

As shown in Figure 19, when the distance between the holes and the double holes is $80 \sim 110 \mathrm{~cm}$, the length of the axial cracks between the double holes increases, and the development rate is approximately the same. This is because, in the gap between the double holes, axial cracks will penetrate in this interval in advance. When the distance between holes reaches $110 \mathrm{~cm}$, the evolution speed of the axial crack length between double holes and nonholes slows down. When the distance between holes reaches $140 \mathrm{~cm}$, the axial crack length between double holes and the growth rate of the longitudinal crack length tend to zero, and the length of the axial crack between the double holes and the axial crack between the double holes is approximately the same. This indicates that the distance between the double holes reaches $140 \mathrm{~cm}$, and the superposition effect of the stress wave produced by double-hole blasting is very small.

\section{Field Experiment}

The Xingquan railway tunnel is selected as the blasting experiment site. Figure 20 shows the shaped charge device after charging.

The rock type of the road section using blasting technology is mainly granite. Ordinary blasting and energyaccumulating blasting structures are applied to on-site construction, and the blasting effects obtained are as follows.

Table 5 shows the design parameters of ordinary blasting, and Table 6 shows the design parameters of shaped blasting. Comparing Tables 5 and 6 shows that the use of shaped charge can achieve a relatively good blasting effect. For the required number of boreholes, the unit consumption of explosives and the utilization rate of boreholes are better than those of the ordinary charge structure. The main difference between the two blasting methods is the number of perimeter holes, as the number of perimeter holes required is less due to the longer crack length after blasting compared to normal blasting. The rock fragmentation degree is better 


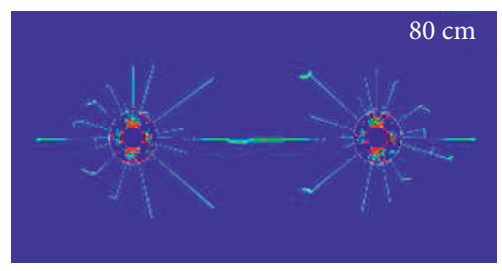

(a)

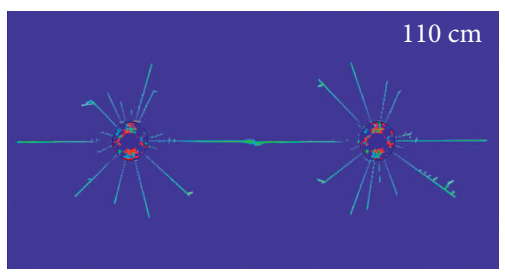

(d)

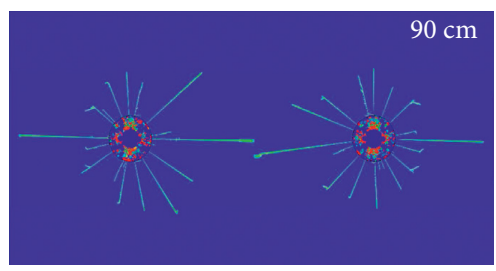

(b)

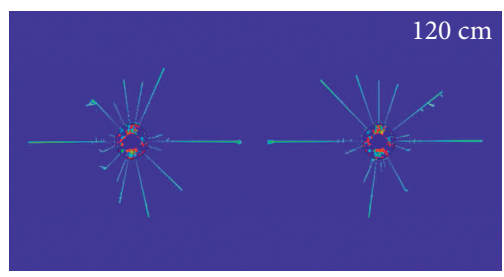

(e)

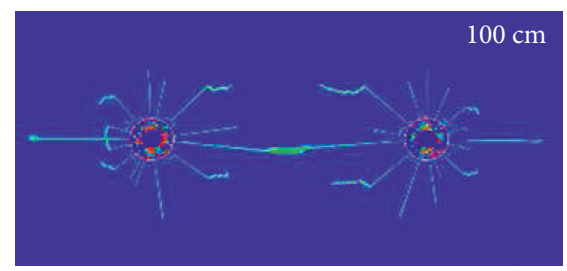

(c)

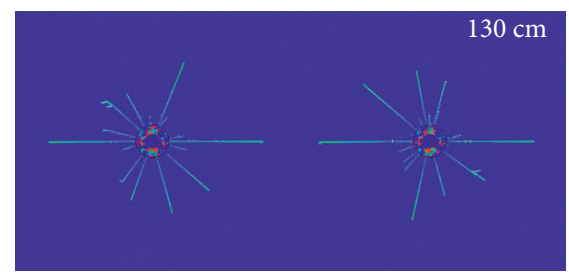

(f)

FIGURE 18: Damage evolution diagram under different borehole spacing.

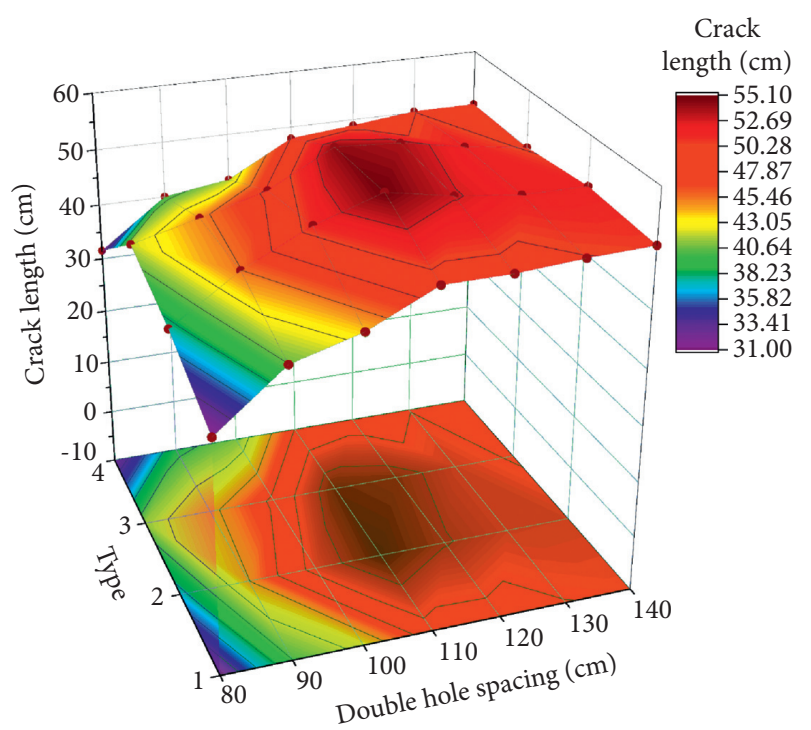

1:Length of left side crack of left hole 2:Length of right side crack of left hole 3:Length of left side crack of right hole 4:Length of right side crack of right hole

FIGURE 19: Crack length under different drilling spacing.

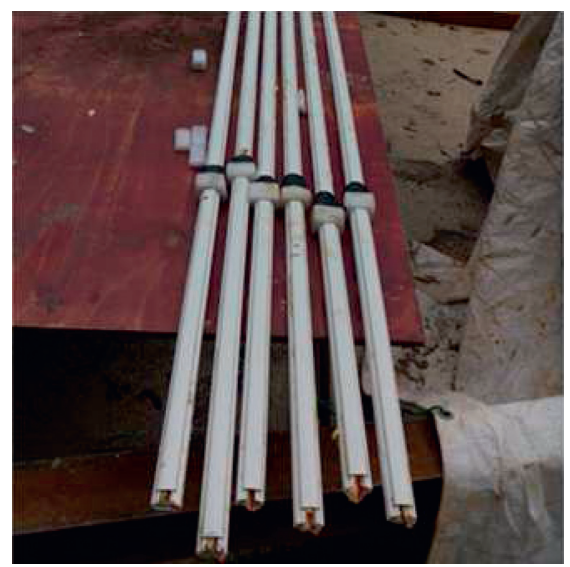

Figure 20: Shaped charge device after charging. 
TABLE 5: Design parameters of ordinary blasting.

\begin{tabular}{|c|c|c|c|c|c|c|c|}
\hline $\begin{array}{l}\text { Type of } \\
\text { borehole }\end{array}$ & $\begin{array}{l}\text { Depth of } \\
\text { hole }(\mathrm{m})\end{array}$ & Number & $\begin{array}{c}\text { Charge of a } \\
\text { borehole }(\mathrm{kg})\end{array}$ & $\begin{array}{c}\text { The total amount of } \\
\text { explosives }(\mathrm{kg})\end{array}$ & $\begin{array}{c}\text { Borehole } \\
\text { utilization (\%) } \\
\end{array}$ & $\begin{array}{c}\text { Degree of rock } \\
\text { fragmentation }(\mathrm{cm})\end{array}$ & $\begin{array}{l}\text { Excavated } \\
\text { area }\left(\mathrm{m}^{2}\right)\end{array}$ \\
\hline $\begin{array}{l}\text { Cutting } \\
\text { undermine }\end{array}$ & 3.0 & 8 & 2.0 & 16 & \multirow{7}{*}{90} & \multirow{7}{*}{36} & \multirow{7}{*}{68.2} \\
\hline $\begin{array}{l}\text { Cut spreader } \\
\text { hole }\end{array}$ & 2.5 & 8 & 1.8 & 14.4 & & & \\
\hline Satellite hole & 2.5 & 27 & 1.4 & 37.8 & & & \\
\hline Inner hole & 2.5 & 20 & 1.3 & 26 & & & \\
\hline Periphery hole & 2.5 & 42 & 0.6 & 25.2 & & & \\
\hline Bottom outlet & 2.6 & 14 & 1.6 & 22.4 & & & \\
\hline Total & & 119 & & 141.8 & & & \\
\hline
\end{tabular}

TABLE 6: Design parameters of shaped blasting.

\begin{tabular}{|c|c|c|c|c|c|c|c|}
\hline $\begin{array}{l}\text { Type of } \\
\text { borehole }\end{array}$ & $\begin{array}{l}\text { Depth of } \\
\text { hole }(\mathrm{m})\end{array}$ & Number & $\begin{array}{c}\text { Charge of a } \\
\text { borehole }(\mathrm{kg})\end{array}$ & $\begin{array}{c}\text { The total amount of } \\
\text { explosives }(\mathrm{kg})\end{array}$ & $\begin{array}{c}\text { Borehole } \\
\text { utilization (\%) }\end{array}$ & $\begin{array}{c}\text { Degree of rock } \\
\text { fragmentation }(\mathrm{cm})\end{array}$ & $\begin{array}{l}\text { Excavated } \\
\text { area }\left(\mathrm{m}^{2}\right)\end{array}$ \\
\hline $\begin{array}{l}\text { Cutting } \\
\text { undermine }\end{array}$ & 3.0 & 8 & 2.0 & 16 & & & \\
\hline $\begin{array}{l}\text { Cut spreader } \\
\text { hole }\end{array}$ & 2.5 & 8 & 1.8 & 14.4 & & & \\
\hline Satellite hole & 2.5 & 27 & 1.4 & 37.8 & 95 & 30 & 68.2 \\
\hline Inner hole & 2.5 & 20 & 1.3 & 26 & & & \\
\hline Periphery hole & 2.5 & 25 & 0.6 & 15 & & & \\
\hline Bottom outlet & 2.6 & 14 & 1.6 & 22.4 & & & \\
\hline Total & & 102 & & 131.6 & & & \\
\hline
\end{tabular}

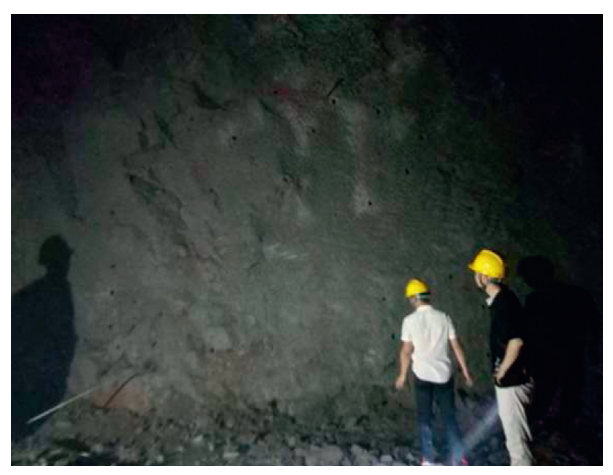

FIgure 21: The tunnel face before blasting.

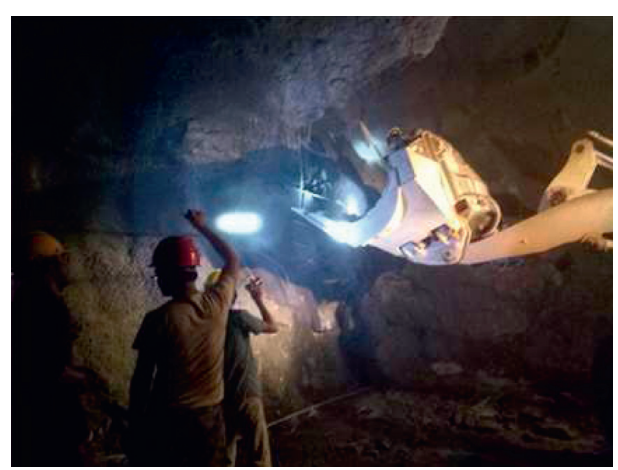

FIgURE 22: The charging process of borehole. 


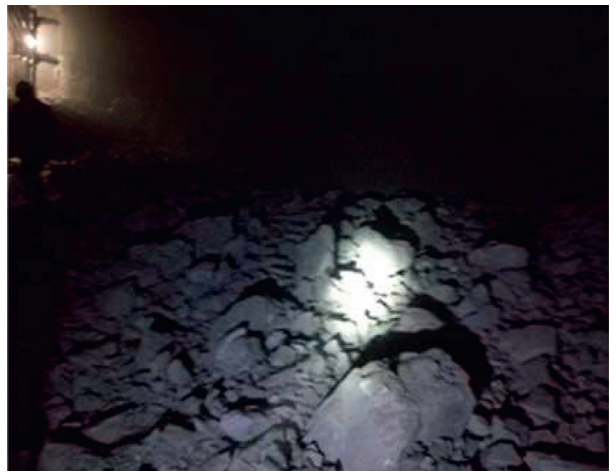

Figure 23: Rocks that fell off after blasting.

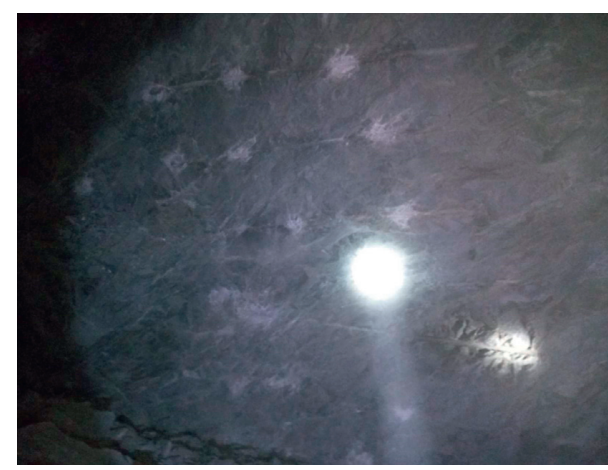

(a)

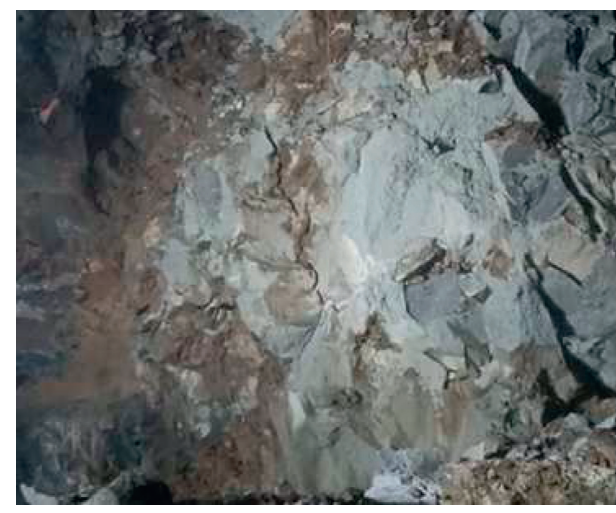

(b)

FIGURE 24: Surrounding rock condition after blasting: (a) shaped blasting and (b) ordinary blasting.

than that of ordinary blasting because the cracks produced by the structure of the shaped charge have a strong guiding type.

Figure 21 shows the tunnel face before blasting. Figure 18 shows that the diameter of the cannon hole in the palm face of the tunnel before blasting is not large, and the diameter of the borehole is $42 \mathrm{~mm}$.

Figure 22 shows the charging process of the borehole in the tunnel. As shown in Figure 23, the fallen rock blocks produced by the shaped energy blasting explosion are wellformed and larger in volume.

Figure 24 shows the overall blasting effect of the surrounding rock after shaped charge blasting and ordinary blasting. Figure 24(a) shows that after adopting the elliptical bipolar linear energy-accumulating blasting structure, a good blasting effect is achieved. The overall shape of the tunnel is better, and the surrounding rock after blasting is relatively smooth and flat, which is conducive to the layout of the support and lining structure.

\section{Conclusion}

To research the rock-breaking mechanism of single and double holes by directional blasting of shaped charge cartridges and optimize the spacing between the double holes, the SPH-FEM coupling algorithm and damage theory are applied to the numerical simulation of rock blasting. The rock parameters are verified, the principle of gather energy directional blasting is revealed, and the response process of rock blasting is reproduced. Based on previous research, the dynamic fracture process between the double holes was numerically simulated, and the spacing between the double holes was optimized.

In the single-hole numerical simulation, the general smooth blasting effect adopted is more consistent with the existing experimental results. On this basis, a good blasting effect is obtained by adopting a shaped charge structure, and the charge quantity is reduced, which reduces the extension of damage cracks in the nongather energy direction and increases the extension of gather energy axial cracks. The optimum blast spacing between the twin holes was $110 \mathrm{~cm}$. Finally, field experiments have verified that the elliptical bipolar linear shaped charge structure can indeed achieve good results in the blasting activities of tunnels.

This paper verifies the directional blasting effect of elliptical bipolar aggregates using numerical simulations and field experiments and obtains the optimum blast spacing between the twin holes. The use of an elliptical bipolar linear charging structure can reduce the number of boreholes in tunnelling, thus reducing the overall charge. It can effectively reduce the over-under-excavation problem in tunnelling, which is of significant engineering application value. 


\section{Data Availability}

The data used to support the findings of this study are available from the corresponding author upon request.

\section{Conflicts of Interest}

The authors declare that there are no conflicts of interest regarding the publication of this study.

\section{Acknowledgments}

The authors would like to express their appreciation for the financial supports from the National Natural Science Foundation of China (nos. 51678164, 51478118, and 52168055), the Guangxi Natural Science Foundation Program (2018GXNSFDA138009), the Guangxi Science and Technology Plan Projects (AD18126011), and the Scientific Research Foundation of Guangxi University (XTZ160590). The authors wish to express thanks to all supporters.

\section{References}

[1] F.-Q. Gong and G.-F. Zhao, "Dynamic indirect tensile strength of sandstone under different loading rates," Rock Mechanics and Rock Engineering, vol. 47, no. 6, pp. 2271-2278, 2014.

[2] W. C. Zhu, L. L. Niu, S. H. Li, and Z. H. Xu, "Dynamic Brazilian test of rock under intermediate strain rate: pendulum hammer-driven SHPB test and numerical simulation," Rock Mechanics and Rock Engineering, vol. 48, no. 5, pp. 1867-1881, 2015.

[3] T. Saksala, "Modelling of dynamic rock fracture process with a rate-dependent combined continuum damage-embedded discontinuity model incorporating microstructure," Rock Mechanics and Rock Engineering, vol. 49, no. 10, pp. 3947-3962, 2016.

[4] L. Dong, D. Sun, X. Li, J. Ma, L. Zhang, and X. Tong, "Interval non-probabilistic reliability of surrounding jointed rockmass considering microseismic loads in mining tunnels," Tunnelling and Underground Space Technology, vol. 81, pp. 326-335, 2018, https://doi.org/10.1016/j.tust.2018.06.034.

[5] C. L. N. Foster, A Treatise of Ore and Stone Mining, Charles Griffin and Company, Glasgow, Scotland, 6 edition, 1905.

[6] M. L. Williams, "Stress singularities resulting from various boundary conditions in angular corners of plates in extension," Journal of Applied Mechanics, vol. 19, no. 4, pp. 526-528, 1952.

[7] M. Henry, Shaped Charges and Warheads, Inc., Englewood Cliffs, New Jersey, 1966.

[8] H. Schardin, Development of the Shaped Charge, Wehrtechnische Hefie, 1954.

[9] G. Bjarnholt, R. Holmberg, and F. Ouchterlong, A Linear Shaped Charge System for Contour blasting[A] Koiiya $C$ C. Proceeding of 9th Conference on Explosives and Blasting technique[C], Society of Explosives Engineers, Dallas, pp. 350-358, 1983.

[10] W. L. Fourney, J. W. Dally, and D. C. Holloway, "Controlled blasting with ligamented charge holders," International Journal of Rock Mechanics and Mining Sciences \& Geomechanics Abstracts, vol. 15, no. 3, pp. 121-129, 1978.
[11] S.-r. Wang and W. You-zhi, "Research on fracture control in rock blasting," Journal of China Institute of Mining and Technology, vol. 14, no. 03, pp. 118-125, 1985.

[12] Q. Jian-fei, Q. Ru-xia, and L. I. Bi-hong, "Study and application of elliptical bipolar linear shaped charge[J]," ENGINEERING BLASTING, vol. 15, no. 03, pp. 70-74, 2009.

[13] Q. Jian-fei, Comprehensive Technology of Dual Energy Presplitting and Smooth Blasting, p. 196, China Water\&Power Press, Beijing, 2014.

[14] L. I. Bi-hong, F. Da-lin, and L. I. Shi-liang, "Study on the presplitting characteristics of elliptical bipolar linear shaped charge," Mining Technology, vol. 11, no. 05, pp. 94-96, 2011.

[15] L. I. Bi-hong, W.-f. Cui, and L. I. Shi-liang, "Experimental investigation and numerical simulation of decouple coefficient of elliptic bipolar linear shaped charge," Blasting, vol. 30, no. 02 , pp. 54-58, 2013.

[16] L. I. Bi-hong, Research on Theory and Application Technology of Elliptic Bipolar Linear Shaped Charge's Presplit Blasting, Central South University, Changsha, 2013.

[17] L. I. Bi-hong, "Numerical simulation and stress testing research on elliptical bipolar linear shaped charge," Journal of Information and Computational Science, vol. 10, no. 11, pp. 3437-3444, 2013.

[18] F.-hao Zhu, L. I. U. Ze-gong, K. Gao et al., "Experimental study on the damage characteristics of surrounding rock during directional accumulation blasting of roadway in structural zone," Chinese Journal of Rock Mechanics and Engineering, vol. 37, no. 09, pp. 2037-2047, 2018.

[19] M. E. N. G. Ning-kang, Y. Chen, B. A. I. Jian-biao, and $\mathrm{X}$. Wang, "Numerical simulation of directional fracturing by shaped charge blasting," Energy Science \& Engineering, vol. 8, no. $5,2020$.

[20] G. R. Johnson and T. J. Holmquist, "An improved computational constitutive model for brittle materials," AIP Conference Proceedings, vol. 309, no. 1, pp. 981-984, 1994.

[21] M. M. D. Banadaki and B. Mohanty, "Numerical simulation of stress wave induced fractures in rock," International Journal of Impact Engineering, vol. 40, no. 2, pp. 16-25, 2012.

[22] Y. Wang, "Analysis of dynamic characteristics of through-wall cracks between 2 boreholes in the directed fracture controlled blasting," Fatigue and Fracture of Engineering Materials and Structures, vol. 41, no. 2, pp. 273-286, 2018.

[23] L. B. Lucy, "A numerical approach to the testing of the fission hypothesis," The Astronomical Journal, vol. 82, no. 12, pp. 1013-1024, 1977.

[24] R. A. Gingold and J. J. Monaghan, "Smoothed particle hydrodynamics: theory and application to non-spherical stars," Monthly Notices of the Royal Astronomical Society, vol. 181, no. 3, pp. 375-389, 1977.

[25] S. Gharehdash, L. M. Shen, Y. X. Gan, and E. A. FloresJohnson, "Numerical investigation on fracturing of rock under blast using coupled finite element method and smoothed particle hydrodynamics," Applied Mechanics and Materials, vol. 846, pp. 102-107, 2016.

[26] G. R. Liu and M. B. Liu, Smoothed Particle Hydrodynamics:a Meshfree Particle Method, World Scientific Publishing Co. Pte. Ltd, Singapore, 2003.

[27] H.-da Liang, G. U. O. Peng-fei, and D.-jie Sun, "A study on crack propagation and stress wave propagation in different blasting modes of shaped energy blasting," Journal of $\mathrm{Vi}$ bration and Shock, vol. 39, no. 04, pp. 157-164+184, 2020. 